\title{
Distance Matters: Biasing Mechanism, Transfer of Asymmetry, and Stereomutation in N-Annulated Perylene Bisimide Supramolecular Polymers
}

Manuel A. Martínez, Azahara Doncel-Giménez, Jesús Cerdá, Joaquín Calbo, Rafael Rodríguez, Juan Aragó, Jeanne Crassous, Enrique Ortí,* and Luis Sánchez*

Cite This: J. Am. Chem. Soc. 2021, 143, 13281-13291

Read Online

ACCESS | Lلlll Metrics \& More | 啨 Article Recommendations | S1 Supporting Information

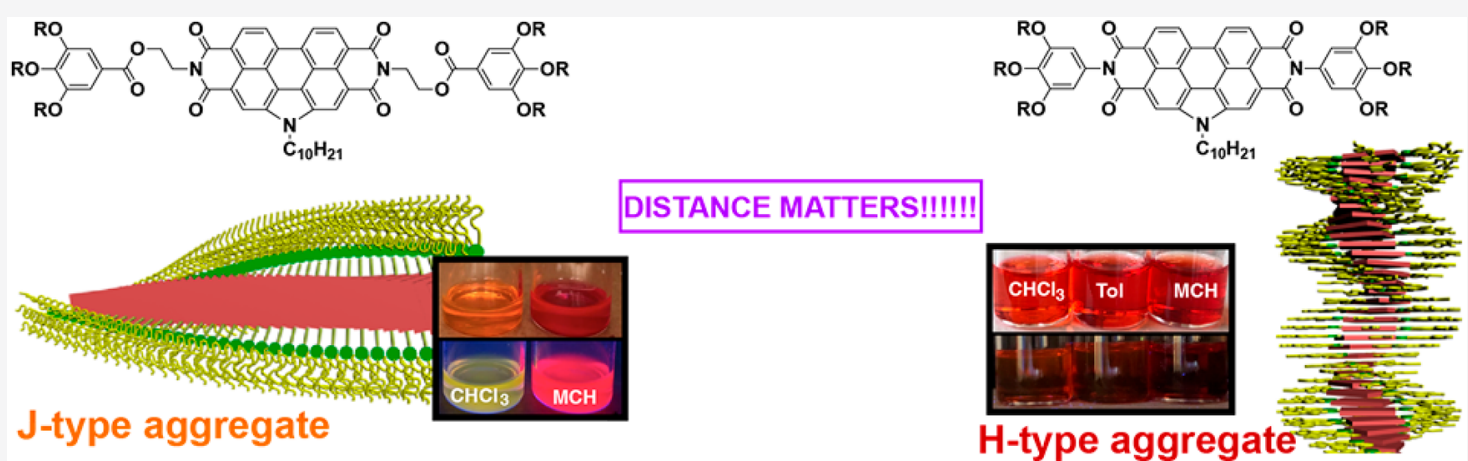

ABSTRACT: The synthesis of two series of $\mathrm{N}$-annulated perylene bisimides (PBIs), compounds $\mathbf{1}$ and 2, is reported, and their selfassembling features are thoroughly investigated by a complete set of spectroscopic measurements and theoretical calculations. The study corroborates the enormous influence that the distance between the PBI core and the peripheral groups exerts on the chiroptical properties and the supramolecular polymerization mechanism. Compounds 1, with the peripheral groups separated from the central PBI core by two methylenes and an ester group, form J-type supramolecular polymers in a cooperative manner but exhibit negligible chiroptical properties. The lack of clear helicity, due to the staircase arrangement of the self-assembling units in the aggregate, justifies these features. In contrast, attaching the peripheral groups directly to the N-annulated PBI core drastically changes the self-assembling properties of compounds 2, which form H-type aggregates following an isodesmic mechanism. These $\mathrm{H}$ type aggregates show a strong aggregation-caused quenching (ACQ) effect that leads to nonemissive aggregates. Chiral (S)-2 and (R)-2 experience an efficient transfer of asymmetry to afford P- and M-type aggregates, respectively, although no amplification of asymmetry is achieved in majority rules or "sergeants-and-soldiers" experiments. A solvent-controlled stereomutation is observed for chiral (S)-2 and (R)-2, which form helical supramolecular polymers of different handedness depending on the solvent (methylcyclohexane or toluene). The stereomutation is accounted for by considering the two possible conformations of the terminal phenyl groups, eclipsed or staggered, which lead to linear or helical self-assemblies, respectively, with different relative stabilities depending on the solvent.

\section{INTRODUCTION}

The molecular recognition by complementary triple hydrogen bonding between diacylaminopyridines and uracil derivatives reported by Lehn and co-workers paved the way to boost the discipline of supramolecular polymerization (SP). ${ }^{1}$ This seminal work, supported by the discovery of J-type aggregates made by Scheibe and Jelley ${ }^{2}$ and the development by Klug and co-workers of the transmission electron microscopy, ${ }^{3}$ prompted an extraordinary progress in the field of supramolecular polymers. ${ }^{4}$ A key issue in the further development of functional supramolecular polymers was the establishment of mathematical models allowing for an accurate description of the SP process. ${ }^{5}$ Two main mechanisms have been amply described to govern the supramolecular polymerization of discrete selfassembling units. The first one, termed isodesmic and comparable to covalent step polymerization, is characterized by a single binding equilibrium constant for all of the supramolecular reactions yielding the final supramolecular polymer. ${ }^{5}$ The second one, named cooperative and related to

Received: June 14, 2021

Published: August 11, 2021 
a)

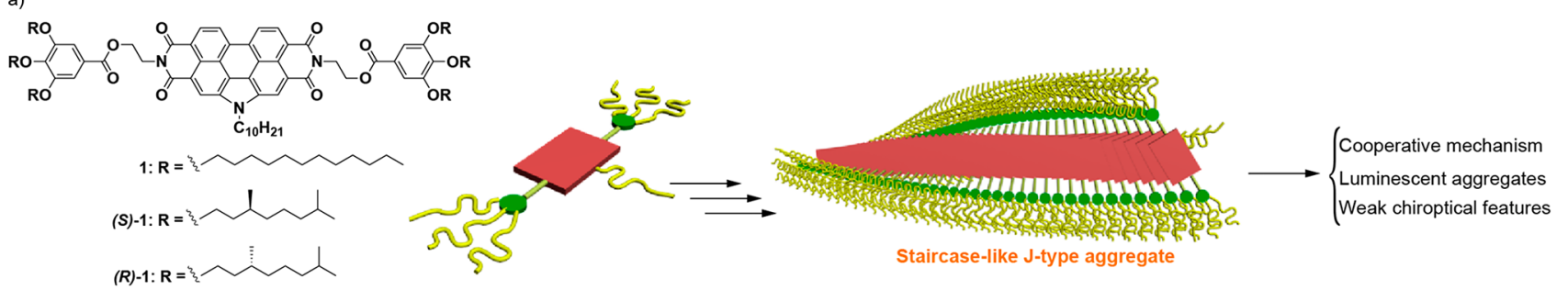

b)
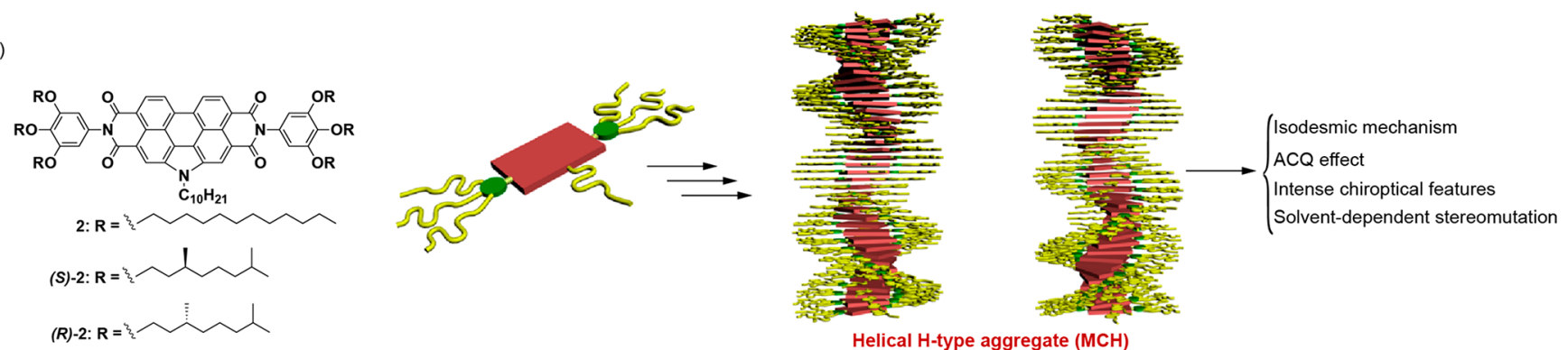

Figure 1. Chemical structure of the N-annulated PBIs 1 (a) and 2 (b) displaying the formation of staircase-like and helical aggregates, respectively, and the derived features of the resulting supramolecular polymers.

covalent chain polymerization, features two binding constants for the extreme regimes of nucleation $\left(K_{\mathrm{n}}\right)$ and elongation $\left(K_{\mathrm{e}}\right)^{5}$ In the nucleation regime, very short aggregates are formed, which, upon overcoming a critical concentration or temperature, elongate to yield the final supramolecular polymer. However, in a cooperative mechanism with $K_{\mathrm{e}} \gg K_{\mathrm{n}}$, the opposite situation is also possible, producing an anticooperative mechanism. ${ }^{5}$ It is worth noting that the investigation of the SP mechanism requires a thermodynamic control of the process. In this regard, a number of exciting examples of pathway complexity, in which a single self-assembling unit is able to generate different aggregates in a competitive or consecutive manner, have been reported in the literature during the past few years. ${ }^{6}$

An intriguing question concerning the investigation of supramolecular polymers relies on establishing clear structure/function relationships that allow predicting and controlling the mechanistic pathway. The first examples of cooperative supramolecular polymers involved (i) the formation of intermolecular H-bonding arrays, (ii) the subsequent conformational changes experienced by the self-assembling units to form these H-bonding interactions, and (iii) the synergy of different noncovalent forces (H-bonding, $\pi$-stacking, hydrophobic interactions, etc.). ${ }^{7}$ These structural requirements were adopted as general rules to attain cooperative pathways. Importantly, George and co-workers demonstrated that permanent dipole-dipole interactions in the direction of polymer growth are the driving force for cooperative mechanisms. ${ }^{8}$ In this sense, some examples of cooperative supramolecular polymers that do not involve $\mathrm{H}$-bonding interactions have been reported. ${ }^{9}$

Supramolecular polymers have found significant applications in different topics. One of these applications relies on the efficient achievement of supramolecular chirality and, more specifically, the generation of helical supramolecular structures. ${ }^{10}$ Supramolecular chirality is usually obtained by the efficient transfer of asymmetry from the molecular to the supramolecular level, starting from self-assembling units bearing elements of asymmetry (point or/and axial chirality). ${ }^{11}$ Amplification of asymmetry, by using sergeants-and-soldiers
( $\mathrm{SaS})$ or majority rules (MR) experiments, is an efficient strategy to attain helical homopolymers from the coassembly of different entities. ${ }^{12}$ Importantly, a cooperative mechanism is behind most of the examples of transfer and amplification of asymmetry in supramolecular polymers, with very few examples being reported for helical supramolecular polymers formed by following isodesmic or weakly cooperative processes. $^{13}$

Herein, we report on the relevant role exerted by the chemical nature and the flexibility of the bridging units separating the peripheral side chains and the central aromatic core constituting the $\mathrm{N}$-annulated perylene bisimide (PBIs) self-assembling units in the supramolecular polymerization (SP) of compounds 1 and $\mathbf{2}$ (Figure 1). While compounds 1 readily form highly luminescent, charge transfer (CT) mediated J-type aggregates in a cooperative manner, ${ }^{14}$ compounds 2 self-assemble into $\mathrm{H}$-type aggregates following an isodesmic mechanism that results in a strong aggregationcaused quenching (ACQ). ${ }^{15}$ The J-type aggregates formed from chiral $(S)-1$ and $(R)-1$ exhibit negligible chiroptical properties, as demonstrated by electronic (ECD) and vibrational (VCD) circular dichroism studies, and a lack of circularly polarized luminescence (CPL). In contrast, the intense and bisignated ECD and VCD spectra displayed by the H-type aggregates formed by $(S)-2$ and $(R)-2$ reveal the formation of helical aggregates with no CPL emission due to the ACQ effect. In addition, chiral $(S)-2$ and $(R)-2$ present a solvent-dependent stereomutation, which can be rationalized by considering the formation of two different self-assemblies (linear vs helical) with opposite stabilities depending on the solvent conditions. The synergy of experimental evidence and theoretical calculations has been used to further justify these findings. Thus, for compounds $\mathbf{1}$, the complementarity between the $\pi$-stacking of the aromatic PBI cores and the electrostatic forces between the peripheral benzoate groups favors the formation of staircase-like aggregates with a nonhelical long-axis-displaced supramolecular structure, leading to negligible chiroptical properties for the resulting J-type aggregates. In contrast, the parallel arrangement of the PBI units, conditioned by the eclipsed or staggered conformation of 

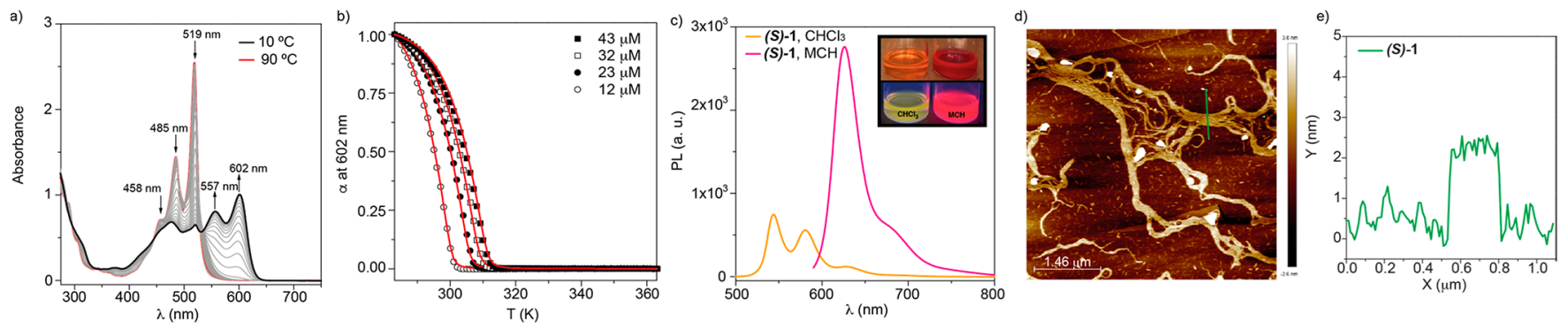

Figure 2. (a) UV-vis spectra of $(S)-1$ at different temperatures $\left(\mathrm{MCH}, c_{\mathrm{T}}=32 \mu \mathrm{M}\right)$. Arrows indicate the absorption changes upon decreasing the temperature from 90 to $10^{\circ} \mathrm{C}$. (b) Plot of the variation of the degree of polymerization $(\alpha)$ of $(S)-1$ in $\mathrm{MCH}$ versus temperature on cooling at 1 ${ }^{\circ} \mathrm{C} \mathrm{min}^{-1}$. Red curves correspond to the fitting to the EQ model. (c) Photoluminescence (PL) spectra of $(S)-1$ in $\mathrm{MCH}\left(\lambda_{\mathrm{exc}}=555 \mathrm{~nm}\right)$ and $\mathrm{CHCl}_{3}\left(\lambda_{\text {exc }}=495 \mathrm{~nm}\right)\left(c_{\mathrm{T}}=10 \mu \mathrm{M}, 298 \mathrm{~K}\right)$. The inset shows the pictures of the solutions of $(S)-1$ in $\mathrm{MCH}$ and $\mathrm{CHCl}_{3}$ used to register the PL spectra without (top samples) and with UV lamp illumination (bottom samples). (d) AFM image and (e) height profile along the green line in (d) of the bundles of fibrillar supramolecular polymers formed by $(S)-1$ in $\mathrm{MCH}$ onto HOPG (spin coating, $\mathcal{c}_{\mathrm{T}}=10 \mu \mathrm{M}, 298 \mathrm{~K}$ ).

Table 1. Thermodynamic Parameters of $(S)-1,(R)-1,2$, and $(S)-2$

\begin{tabular}{|c|c|c|c|c|}
\hline & $(S)-1^{a}$ & $(R)-1^{a}$ & $2^{b}$ & $(S)-2^{b}$ \\
\hline$\Delta H_{\mathrm{e}}\left(\mathrm{kJ} \mathrm{mol}^{-1}\right)$ & $-91.4 \pm 0.5$ & $-93.9 \pm 0.4$ & $-77.0 \pm 0.7$ & $-78.9 \pm 0.6$ \\
\hline$\Delta S\left(\mathrm{~J} \mathrm{~mol}^{-1}\right)$ & $-211 \pm 1$ & $-219 \pm 1$ & $-137 \pm 2$ & $-141 \pm 1$ \\
\hline$\Delta H_{\mathrm{n}}\left(\mathrm{kJ} \mathrm{mol}{ }^{-1}\right)^{c}$ & $-16.2 \pm 0.2$ & $-16.5 \pm 0.2$ & $-77.0 \pm 0.7^{d}$ & $-78.9 \pm 0.6^{d}$ \\
\hline$\sigma^{c}$ & $1.2 \times 10^{-3}$ & $1.1 \times 10^{-3}$ & 1 & 1 \\
\hline$K_{\mathrm{e}}\left(\mathrm{L} \mathrm{mol}^{-1}\right)^{c}$ & $1.9 \times 10^{5}$ & $2.0 \times 10^{5}$ & $3.7 \times 10^{6}$ & $5.1 \times 10^{6}$ \\
\hline$K_{\mathrm{n}}\left(\mathrm{L} \mathrm{mol}^{-1}\right)^{c}$ & $2.4 \times 10^{2}$ & $2.2 \times 10^{2}$ & & \\
\hline
\end{tabular}

${ }^{a}$ In MCH. ${ }^{b}$ In decalin. ${ }^{c}$ The equilibrium constants for elongation $\left(K_{\mathrm{e}}\right)$ and dimerization $\left(K_{\mathrm{n}}\right)$ and the cooperativity factor $\sigma\left(=K_{\mathrm{n}} / K_{\mathrm{e}}\right)$ were calculated at $298 \mathrm{~K}$. ${ }^{d}$ When the isodesmic nature of the supramolecular polymerization of compounds 2 is considered, the values of $\Delta H_{\mathrm{e}}$ and $\Delta H_{\mathrm{n}}$ are equal.

the peripheral trialkoxyphenyl moieties directly attached to the PBI core in 2, is responsible for the formation of $\mathrm{H}$-type aggregates that experience a solvent-dependent stereomutation. The studies presented in this manuscript contribute to the elaboration of structure/function relationships that are useful to predict relevant features of supramolecular polymers.

\section{RESULTS AND DISCUSSION}

Synthesis and Supramolecular Polymerization Mechanism. The synthesis of $\mathrm{N}$-annulated PBIs $\mathbf{1}$ and $\mathbf{2}$ was accomplished by following a procedure similar to that reported for achiral 1, in which the corresponding chiral 2-aminoethyl 3,4,5-trialkoxybenzoate 9 (for (S)-1 and (R)-1) or 3,4,5trialkoxyaniline 14 (for 2, (S)-2, and (R)-2) was reacted with $\mathrm{N}$-annulated perylene-3,4,9,10-tetracarboxylic dianhydride 5 in the presence of $\mathrm{Zn}(\mathrm{AcO})_{2}$ and imidazole. ${ }^{14}$ All of the new compounds were characterized by common spectroscopic techniques. A complete description of the synthetic protocols and the spectroscopic characterization is included in the Supporting Information.

A detailed investigation of the supramolecular polymerization mechanism of the chiral (S)-1 and (R)-1 was performed, resting on the previous results on achiral $\mathbf{1}^{14}$ The synergy of experimental and theoretical studies on 1 demonstrated the formation of J-type aggregates by the $\pi$ stacking of the aromatic moieties with the pyrrolic rings of the adjacent monomers pointing to the same direction. These noncovalent forces are also operative in the self-assembly of chiral (S)-1 and (R)-1 (Figure S1). Variable-temperature (VT) $\mathrm{UV}-$ vis experiments in methylcyclohexane $(\mathrm{MCH})$ as solvent proved that the supramolecular polymerization mechanism of 1 occurs in a cooperative manner under thermodynamic control, since no thermal hysteresis is observed in the cooling and heating curves. ${ }^{14}$ In good analogy, chiral $(S)-1$ and $(R)-1$ present similar self-assembling features (Figure S2a). Thus, the monomeric state of these chiral $\mathrm{N}$-annulated PBIs, attained by heating up diluted solutions of these compounds at $90{ }^{\circ} \mathrm{C}$, shows two absorption peaks at 485 and $519 \mathrm{~nm}$, ascribable to the $\mathrm{A}_{0-1} / \mathrm{A}_{0-0}$ transitions (Figure 2a). ${ }^{16}$ This absorption pattern coincides with that observed by using a "good" solvent such as chloroform (Figure S2b). Cooling these solutions provokes the red shift of the absorption bands to 557 and 602 $\mathrm{nm}$, diagnostic of the formation of J-type aggregates (Figure $2 a$ ). The depletion of the absorption peaks at 485 and $519 \mathrm{~nm}$ and the increase in the peaks at 557 and $602 \mathrm{~nm}$ upon cooling presents a nonsigmoidal shape characteristic of a cooperative mechanism. The global fitting of the variation of the degree of aggregation $\alpha$ versus temperature to the equilibrium (EQ) model $^{17}$ (Figure 2b and Figure S3) allows derivation of all the thermodynamic parameters (nucleation $\left(\Delta H_{\mathrm{n}}\right)$ and elongation $\left(\Delta H_{\mathrm{e}}\right)$ enthalpies, entropy $(\Delta S)$, nucleation $\left(K_{\mathrm{n}}\right)$ and elongation $\left(K_{\mathrm{e}}\right)$ binding constants, and the degree of cooperativity $\sigma$ ) associated with the supramolecular polymerization of these chiral compounds, which are similar to those derived for achiral $\mathbf{1}$ (Table 1$){ }^{14}$

The formation of J-type aggregates for compounds $\mathbf{1}$ has also been confirmed by the intense emission of a $\mathrm{MCH}$ solution of (S)-1 at $\mathcal{c}_{\mathrm{T}}=10 \mu \mathrm{M}$ (Figure 2c). The fluorescence spectrum shows a sharp band centered at $626 \mathrm{~nm}$ with a shoulder at 684 $\mathrm{nm}$, which presents a small Stokes shift between the absorption and the emission maxima of $24 \mathrm{~nm}$, characteristic of J-type aggregates. ${ }^{18}$ The photoluminescent quantum yield $\left(\Phi_{\text {lum }}\right)$ and the lifetime $(\tau)$ estimated for the aggregated species show values of 0.716 and $5.7 \mathrm{~ns}$, respectively (Table S1). These emission features contrast with those observed in $\mathrm{CHCl}_{3}$, in which a much less intense spectrum, displaying maxima at 543 
and $581 \mathrm{~nm}$, is observed with lower values of $\Phi_{\text {lum }}(0.191)$ and $\tau$ (1.91 ns) (Figure $2 \mathrm{c}$ and Table S1). The aggregation of these $\mathrm{N}$-annulated perylenes is recognizable by the naked eye through a color change of the solution from orange to deep red, with a clear change in the fluorescence under illumination (Figure 2c, inset). The morphology of the aggregates formed upon the supramolecular polymerization of $(S)-1$ was visualized by atomic force microscopy (AFM) imaging employing highly oriented pyrolytic graphite (HOPG) as the surface. The AFM images recorded for the samples deposited onto HOPG show the formation of fibrillar aggregates bundled in highly uniform strips constituted by fibers with a typical height of $2.5 \mathrm{~nm}$ (Figure 2d,e and Figure S4).

To investigate the geometrical structure of the J-type aggregates, a conformational theoretical study on a simplified monomer of 1, bearing flexible ethyl benzoate peripheral groups and methyl groups on the amine nitrogens, was first performed at the semiempirical GFN2-xTB level using the conformer-rotamer ensemble sampling tool (CREST). ${ }^{19}$ Among all the structural possibilities and despite the higher stability of conformer I, only conformers II and III shown in Figure S5 are able to undergo self-assembly. Therefore, conformers II and III were used to build up the most plausible supramolecular pentamers, which were fully optimized through the cost-effective GFN2-xTB method. Pentamers $\mathbf{1 A}_{\mathbf{5}}$ and $\mathbf{1 B}_{5}$ in parts $\mathrm{a}$ and $\mathrm{b}$ of Figure 3, respectively, correspond to the

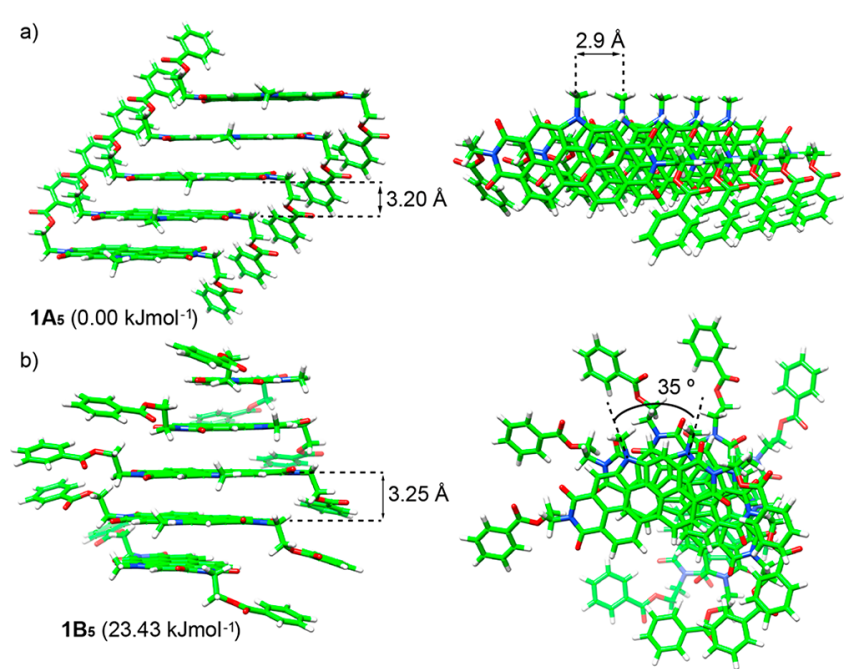

Figure 3. Minimum-energy structures (with their relative energies indicated) calculated at the GFN2-xTB level for the most stable pentamers $\mathbf{1 A}_{\mathbf{5}}$ (a) and $\mathbf{1 B}_{5}$ (b) in the self-assembly of $\mathbf{1}$.

most stable aggregates found and show a $\pi$-stacking of the aromatic PBI cores with an anti disposition of the peripheral benzoate groups. The lowest-energy aggregate $\mathbf{1 A}_{\mathbf{5}}$ grows up with a shift of approximately $2.90 \AA$ along the long axis of the central $\mathrm{N}$-annulated PBI, and an intermolecular distance of

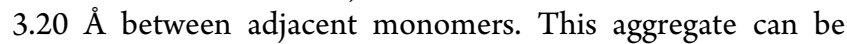
initially considered as a typical J-type self-assembly. In contrast, aggregate $\mathbf{1 B}_{5}$, which is calculated $23.4 \mathrm{~kJ} \mathrm{~mol}^{-1}$ higher in energy compared to $\mathbf{1 A}_{\mathbf{5}}$ (GFN2-xTB level in gas phase), selfassembles with a rotational angle $(\theta)$ of $35.0^{\circ}$, a growing axis shifted approximately $2.90 \AA$ with respect to the center of the PBI core, and an intermolecular core-to-core distance of 3.25 $\AA$. The stabilizing noncovalent interactions present in both structures are the $\pi$-stacking of the central aromatic moieties, as evidenced by the ${ }^{1} \mathrm{H}$ NMR spectra shown in Figure S1, and between the peripheral benzoate groups of vicinal molecules, with $\mathrm{CH} \cdots \mathrm{O}$ contacts of $2.40 \AA\left(\mathbf{1 A}_{5}\right)$ and $2.73-2.94 \AA\left(\mathbf{1 B}_{5}\right)$, and the $\mathrm{C}=\mathrm{O}$ dipole-dipole electrostatic interactions between vicinal benzoates. From now on, we will focus on the most stable $\mathbf{1} \mathbf{A}_{5}$ aggregate, which grows up as a staircase-like aggregate with a negligible helical long-axis-displaced supramolecular structure (Figure S6).

The self-assembled model $\mathbf{1} \mathbf{A}_{\mathbf{5}}$ was used to further shed light on the cooperative SP mechanism experimentally observed for compounds 1 . Thus, the binding energy per interacting pair $\left(\Delta E_{\text {bind,--1 }}\right)$, computed at the GFN2-xTB level for $\mathbf{1 A}_{\mathbf{5}}$-based oligomers in $n$-hexane as solvent and as a function of the oligomer size $n$, displays a rapid decay from the dimer $(-76.2$ $\mathrm{kJ} \mathrm{mol}^{-1}$ ) to the decamer $\left(-91.5 \mathrm{~kJ} \mathrm{~mol}^{-1}\right.$ ) (Figure S7). After $n=10$, the decrease in $\Delta E_{\text {bind }, n-1}$ is attenuated, and $\Delta E_{\text {bind, } n-1}$ converges to a value of $\mathrm{ca}$. $-94 \mathrm{~kJ} / \mathrm{mol}$ when $n=\infty$. This trend in $\Delta E_{\mathrm{bind}, n-1}$ confirms a nucleation-elongation SP mechanism, where the initial fast decay is associated with the nucleation and the attenuated part is related to the elongation process in which the addition of extra molecules has no significant effect on the stabilization energy of the aggregate. The presence of different noncovalent interactions stabilizing the self-assembly (especially $\pi$-stacking interactions along with oriented $\mathrm{C}=\mathrm{O}$ dipole-dipole forces) may explain the cooperativity of the supramolecular growth mechanism in $\mathbf{1}$.

The optical properties of 1 were studied by means of timedependent density functional theory (TD-DFT) calculations along with a vibronic excitonic model, similar to that proposed by Spano and co-workers, to deal with the optical properties in the aggregated state (see the Supporting Information for full details). ${ }^{20}$ Experimentally, the UV-vis spectrum of the molecularly dissolved state of 1 shows two strong bands at 485 and $519 \mathrm{~nm}$ (Figure 2a). These bands are attributed to the vibrational structure $\left(\mathrm{A}_{0-1} / \mathrm{A}_{0-0}\right.$ vibronic transitions $)$ associated with the lowest-lying $S_{0} \rightarrow S_{1}$ electronic excitation according to the simulated absorption spectrum (including vibrational resolution) calculated for a core model of $\mathbf{1}$ in its monomeric form (Figure S8). The theoretical spectrum predicts two strong bands at 460 and $500 \mathrm{~nm}$, in good agreement with the experimental spectrum, and confirms that the absorption features of $\mathbf{1}$ mainly result from the $\mathrm{N}$ annulated PBI core. The absorption spectrum of the aggregate was theoretically calculated by using an excitonic model including not only local excitations (Frenkel-type states) but also charge-transfer (CT) states. The latter have been demonstrated to be relevant for the optical properties of PBI-based self-assemblies. ${ }^{21,22}$ Figure S8 shows the simulated absorption spectrum for an ideal $\mathbf{1 A}_{\mathbf{1 0}}$ aggregate. The spectrum exhibits two well-separated absorption bands (peaking at ca. 430 and $600 \mathrm{~nm}$ ) accompanied by their corresponding vibrational structure. These spectral features are characteristic of a CT-mediated J-type aggregate and explain the broad and vibrationally resolved experimental band observed in the 400$650 \mathrm{~nm}$ range (Figure 2a)..$^{20,21}$

The situation changes drastically in compounds 2 , in which the peripheral trialkoxyphenyl units are directly attached to the $\mathrm{N}$-annulated PBI core (Figure 1a). Similarly to compounds 1, concentration-dependent ${ }^{1} \mathrm{H}$ NMR spectra of 2 display the downfield shift of the three sets of aromatic resonances upon decreasing the concentration with a minor shift of the aliphatic protons, indicating the $\pi$-stacking of the aromatic units (Figure S9). To unveil the arrangement of the monomeric units of 

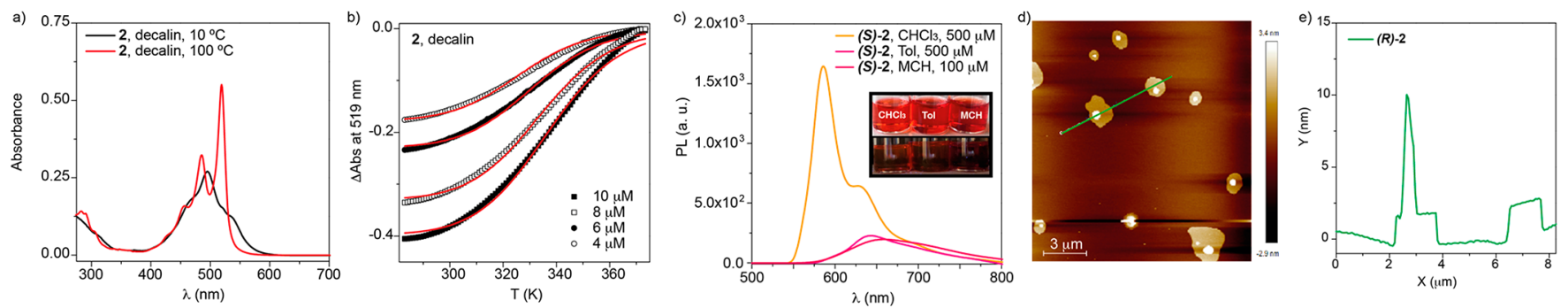

Figure 4. (a) UV-vis spectra of 2 at different temperatures (decalin, $c_{\mathrm{T}}=10 \mu \mathrm{M}$ ). (b) Plot of the variation of the absorbance measured at $519 \mathrm{~nm}$ versus cooling at $1{ }^{\circ} \mathrm{C} \mathrm{min}^{-1}$. Red curves correspond to the fitting to the EQ model. (c) PL spectra of $(S)-2$ in $\mathrm{MCH}_{\text {, toluene, and } \mathrm{CHCl}}\left(\lambda_{\mathrm{exc}}=\right.$ $380 \mathrm{~nm}, 298 \mathrm{~K}$ ). The inset shows pictures of the solutions of $(S)-2$ in $\mathrm{MCH}$, Tol, and $\mathrm{CHCl}_{3}$ used to register the PL spectra without (top samples) and with illumination (bottom samples). (d) AFM image and (e) height profile along the green line in (d) of the supramolecular polymers formed by $(\boldsymbol{R})-2$ in $\mathrm{MCH}$ onto HOPG (spin coating; $\mathcal{c}_{\mathrm{T}}=10 \mu \mathrm{M}, 298 \mathrm{~K}$ ).

compounds 2 in forming the corresponding supramolecular polymers and the mechanism governing their SP, VT-UV-vis experiments were first performed in $\mathrm{MCH}$ as solvent. Unlike compounds 1 , the absorption pattern of achiral 2 in $\mathrm{MCH}\left(c_{\mathrm{T}}\right.$ $=10 \mu \mathrm{M}, 20{ }^{\circ} \mathrm{C}$ ) shows a broad band centered at $494 \mathrm{~nm}$ with shoulders at 463 and $537 \mathrm{~nm}$, apparently characteristic of $\mathrm{H}$ type aggregates (Figure S10a). ${ }^{18}$ Heating this solution to $90{ }^{\circ} \mathrm{C}$ changes the absorption profile, and bands at 517 and $485 \mathrm{~nm}$, ascribable to the monomeric state of the $\mathrm{N}$-annulated PBI core, are observed. However, the intensity ratio between these two bands does not correspond to that recorded in "good" solvents such as $\mathrm{CHCl}_{3}$ and toluene (Tol), in which the fully molecularly dissolved state is achieved (Figure S10b). In fact, plotting the variation of the absorption at $517 \mathrm{~nm}$ versus temperature results in an incomplete cooling curve that resembles a sigmoidal shape, thus indicating an isodesmic mechanism (Figure S10c). This incomplete disassembly of the supramolecular polymers of $\mathbf{2}$ in $\mathrm{MCH}$ is also observed by decreasing $c_{\mathrm{T}}$ to $5 \mu \mathrm{M}$ (Figure S11) or for the chiral congener (S)-2 (Figure S12a).

To achieve a complete disassembly of the aggregates of $\mathrm{N}$ annulated PBIs 2 that allows us to elucidate the SP mechanism and to infer the corresponding thermodynamic parameters, we used decalin as the solvent due to its higher boiling point in comparison to $\mathrm{MCH}$. The UV-vis spectrum of the aggregated species of $\mathbf{2}$ in decalin presents an absorption profile identical with that registered in $\mathrm{MCH}$ (Figure 4a). However, on heating to $100{ }^{\circ} \mathrm{C}$, it is possible to achieve a complete disassembly, as indicated by the relative intensity of the characteristic $\mathrm{A}_{0-1}$ / $\mathrm{A}_{0-0}$ vibronic transitions (Figure $4 \mathrm{a}$ ). In good analogy with compounds 1, no thermal hysteresis is observed in the cooling and heating curves, which indicates that the supramolecular polymerization of $\mathbf{2}$ takes place under thermodynamic control (Figure S12b). Plotting the variation of the absorbance at 519 $\mathrm{nm}$ versus temperature results in sigmoidal curves that, upon global fitting to the one-component EQ model, yields the thermodynamic parameters associated with the isodesmic formation of the H-type aggregates (Figure 4b, Figure S13, and Table 1). It is worth noting that, despite the lower values of $\Delta H_{\mathrm{e}}$ for compounds 2 in comparison to those derived for compounds 1 and the similar entropies for both 1 and 2, the binding constants for these $\mathrm{H}$-type aggregates are one order of magnitude higher than those calculated for the J-type aggregates formed by compounds 1 (Table 1). This difference in the stability of the aggregates is justified by the nucleation penalty present in the cooperative formation of the head-to-tail supramolecular polymers of $\mathbf{1}$. The face-to-face arrangement of the self-assembling units of compounds 2 in the H-type aggregates is also confirmed by the strong ACQ effect observed in the fluorescence spectra (Figure 4c). In good analogy to compounds 1, N-annulated PBIs 2 show an emission spectrum in $\mathrm{CHCl}_{3}$ featuring two bands at 586 and $630 \mathrm{~nm}$ with a Stokes shift of $53 \mathrm{~nm}$ (Figure 4c). In contrast, the emission spectrum of the supramolecular polymers of 2 in $\mathrm{MCH}$ shows an unstructured, broad band of very low intensity centered at 662 $\mathrm{nm}$ and a large Stokes shift $(\sim 160 \mathrm{~nm})$ (Figure $4 \mathrm{c}$ ).

The morphology of the H-type aggregates formed from achiral 2 was visualized by AFM. The AFM images of 2 show the formation of 2D nanosheets with diameters of a few micrometers and uniform heights of $\sim 1.6 \mathrm{~nm}$. On top of these $2 \mathrm{D}$ nanosheets, the presence of high micellar aggregates with $\sim 450 \mathrm{~nm}$ thickness and $\sim 8.5 \mathrm{~nm}$ height is also observed (Figure 4d,e and Figure S14).

To justify the sharp differences found in the supramolecular polymerization of compounds 2 in comparison to compounds $\mathbf{1}$, the monomeric and aggregated states of $\mathbf{2}$ were theoretically investigated at the GFN2-xTB level. ${ }^{19}$ As was previously done for compounds 1, the peripheral alkoxy chains present in the chemical structure of $\mathbf{2}$ were removed to reduce the computational cost. Due to the more rigid structure of 2, only two possible conformers, differing in the eclipsed (2A) or staggered (2B) disposition of the peripheral benzene rings with respect to the long PBI axis, are possible and they were computed to be practically isoenergetic (Figure 5a). Similarly to $\mathbf{1}$, the supramolecular pentamers $\mathbf{2} \mathbf{A}_{5}$ and $\mathbf{2} \mathbf{B}_{5}$ were modeled and were fully optimized at the GFN2-xTB level (Figure 5b). In both aggregates, the pyrrolic units of the central PBI cores are arranged in the most favorable parallel distribution along the stacking axis, as demonstrated previously. ${ }^{14}$ The helical aggregate $\mathbf{2 B}_{5}$, which stems from monomers $\mathbf{2 B}$ with the peripheral aromatic groups in a staggered disposition, was calculated to be more stable by a small energy difference of $18.61 \mathrm{~kJ} \mathrm{~mol}^{-1} \cdot \mathbf{2 B}_{5}$ grows with a rotational angle $(\theta)$ of $35.8^{\circ}$ along a stacking axis that is shifted ca. $2.90 \AA$ with respect to the center of the perylene scaffold. Adjacent molecules in $\mathbf{2 B}_{\mathbf{5}}$ are separated by an intermolecular distance of $3.20 \AA$ between the aromatic cores and are arranged with the pyrrole moieties pointing out of the stack. In contrast, aggregate $2 \mathbf{A}_{5}$, built up from monomers $\mathbf{2 A}$ displaying an eclipsed conformation of the phenyl groups, grows in a slipped manner with a shift of $2.43 \AA$ along the short PBI axis and an intermolecular distance of 3.35 $\AA$ between consecutive aromatic cores. In both structures, stabilizing noncovalent intermolecular interactions due to the $\pi$-stacking of both the central PBI cores and the peripheral phenyl groups and to the $\mathrm{CH}$ (phenyl) $\cdots \mathrm{O}$ interactions (distances of $2.02 \AA$ in $\mathbf{2} \mathbf{A}_{5}$ and $2.25-2.48 \AA$ in $\mathbf{2} \mathbf{B}_{5}$ ) are 


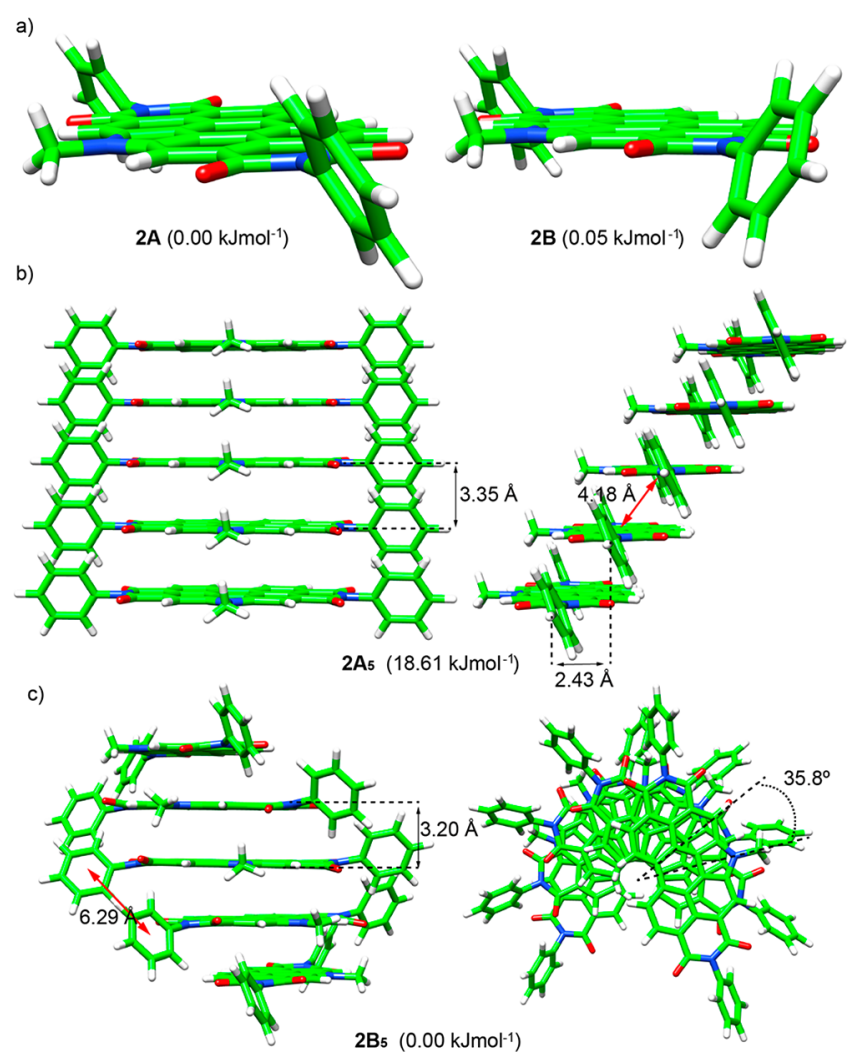

Figure 5. Minimum-energy structures (with their relative energies indicated) calculated at the GFN2-xTB level for the most stable monomers $\mathbf{2 A}$ and $\mathbf{2 B}$ (a) and for pentamers $2 \mathbf{A}_{5}$ (b) and $\mathbf{2} \mathbf{B}_{5}$ (c) in the self-assembly of $\mathbf{2}$.

present (Figure $5 \mathrm{~b}$ ). Pentamers $\mathbf{2 A}_{\mathbf{5}}$ and $\mathbf{2} \mathbf{B}_{\mathbf{5}}$ can both be initially considered as $\mathrm{H}$-type aggregates.

To get further insight into the spectroscopic features displayed by compounds 2, TD-DFT theoretical calculations and the excitonic model mentioned above were used to compute the UV-vis spectra. Figure S15 displays the simulated absorption spectra for ideal $\mathbf{2} \mathbf{A}_{10}$ and $\mathbf{2} \mathbf{B}_{10}$ decamers. A broad vibrationally resolved absorption band is obtained for both aggregates, although with different spectral profiles. The pattern predicted for $\mathbf{2} \mathbf{B}_{\mathbf{1 0}}$ is especially in good accord with that experimentally registered in decalin for the supramolecular polymers formed from compounds 2 (Figure $4 \mathrm{a}$ ) and confirms the H-type nature of this aggregate. It is important to note that, as discussed below, 2B supramolecular oligomers are more stable than 2A oligomers in apolar solvents.

Chiroptical Features: Transfer and Amplification of Asymmetry. ${ }^{23}$ The decoration of compounds (S)-1, (R)-1, $(S)-2$, and (R)-2 with chiral side chains, together with the studies on the supramolecular polymerization of these $\mathrm{N}$ annulated PBIs discussed above, allows performing a detailed investigation on the transfer and amplification of asymmetry resulting from these self-assembling units.

The cooperative supramolecular polymerization found for compounds 1 was expected to yield an efficient transfer of asymmetry from the molecular to the supramolecular level. Previous examples of J-type aggregates have been reported to give rise to helical aggregates, as demonstrated by the corresponding ECD spectra. ${ }^{24}$ To our surprise, the ECD spectra of the J-type aggregates formed by $(S)-1$ and $(R)-\mathbf{1}$ in $\mathrm{MCH}$ display a very weak and noisy dichroic response with maxima at 260 and $591 \mathrm{~nm}$ and the anisotropy factor $g \approx 1 \times$ $10^{-4}$ (Figure 6a). The negligible chiroptical response observed
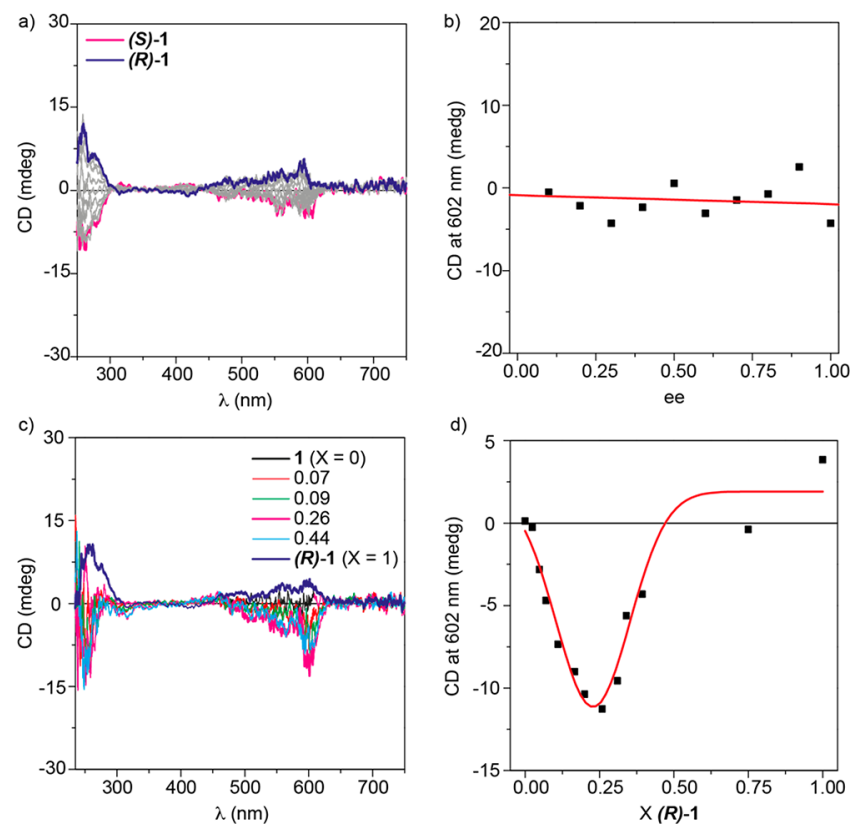

Figure 6. Amplification-of-asymmetry experiments performed with $\mathrm{N}$ annulated PBIs 1. (a) ECD spectra for MR experiments. (b) Changes in ECD intensity at $602 \mathrm{~nm}$ as a function of the ee upon adding $(R)-1$ to a solution of (S)-1. (c) Selected ECD spectra registered for the SaS experiments performed by mixing 1 and (R)-1. (d) Changes in the ECD intensity at $602 \mathrm{~nm}$ upon increasing the molar fraction (X) of the chiral sergeant $(R)-1$. The red line in (d) corresponds to a Gaussian fit to guide the eye. Experimental conditions: $\mathrm{MCH}, c_{\mathrm{T}}=50$ $\mu \mathrm{M}, 20{ }^{\circ} \mathrm{C}$

for compounds $\mathbf{1}$ is in agreement with the nonhelical long-axisdisplaced supramolecular structure theoretically predicted for the aggregates derived from 1 (Figure $3 \mathrm{a}$ ). The lack of dichroic response is also corroborated by the noisy VCD spectra recorded for $(S)-1$ and $(R)-1$, which contrasts with the welldefined FTIR spectra of these N-annulated PBIs in solution, where the bands corresponding to the imide and ester carbonyls (1714 and $1692 \mathrm{~cm}^{-1}$ ) and to the aryl alkyl ethers (1218 and $1118 \mathrm{~cm}^{-1}$ ) are clearly visible (Figure S16). In addition, and despite the strong emission of the supramolecular polymers formed by these chiral $\mathrm{N}$-annulated PBIs (Figure 2c), no CPL signal is observed (Figure S17a).

We also evaluated the ability of chiral $\mathrm{N}$-annulated PBIs 1 to undergo amplification of asymmetry by developing majority rules (MR) and sergeants-and-soldiers $(\mathrm{SaS})$ experiments. ${ }^{11 \mathrm{a}, 12}$ In the MR experiments, unequal amounts of the two enantiomers $(S)-1$ and $(R)-1$, with the total concentration kept constant, are mixed together. In this case, the ECD spectra registered at different $(S)-1 /(R)-1$ ratios show the same weak and noisy profile as that registered for pristine enantiomers (Figure 6a). In addition, plotting the variation of the poor dichroic response at $602 \mathrm{~nm}$ versus the enantiomeric excess (ee) results in a linear trend, which indicates either the negligible ability of these compounds to coassemble into homochiral aggregates or the inability of detecting this phenomenon due to the poor dichroic response (Figure $6 \mathrm{~b}$ ). The lack of a clear dichroic (ECD, VCD, CPL) response for the supramolecular polymers formed by $(S)-1$ and $(R)-1$, 
despite the cooperative character of their supramolecular polymerization, is accounted for by the staircaselike aggregation mode (Figures 1a and 3a and Figure S6) that yields a nonhelical supramolecular structure.

The SaS experiments, performed by mixing the achiral soldier $\mathbf{1}$ and the chiral sergeant ( $R$ )-1, produce an abnormal effect by which the sign of the dichroic signal detected for relatively low molar fractions $(\mathrm{X})$ of $(\boldsymbol{R})-\mathbf{1}$ is reversed with respect to that recorded for the pristine chiral seargent (Figure $6 c, d)$. The weak dichroic response attained in the ECD spectra could suggest that this effect is an artifact. However, an analogous effect but of opposite sign is observed for the SaS experiments carried out by mixing $\mathbf{1}$ and (S)-1 (Figure S18). We have previously described a similar effect for selfassembling units able to form intramolecular hydrogen-bonded metastable monomers that retard the corresponding supramolecular polymerization. ${ }^{25}$ However, this is not the case, since $\mathrm{N}$-annulated PBIs 1 cannot form $\mathrm{H}$-bonded metastable monomers and their supramolecular polymerization is under thermodynamic control. A similar abnormal $\mathrm{SaS}$ effect has been described for covalent polymers and justified by considering the different energy preferences exhibited by the situation in which a chiral sergeant is adjacent to another chiral sergeant or to an achiral soldier. This energy difference conditions the sign of the dichroic response. ${ }^{26}$

In contrast to $\mathbf{1}$, the transfer of asymmetry from the molecular to the supramolecular level in $\mathrm{N}$-annulated PBIs (S)-2 and (R)-2 yields a rich dichroic pattern, with an intense bisignated Cotton effect with maxima at 490 and $547 \mathrm{~nm}$ and zero crossing points at 508, 344, 278, and $261 \mathrm{~nm}$ and with the anisotropy factor $g \approx 3 \times 10^{-3}$ (Figure $7 \mathrm{a}$ ). This bisignated Cotton effect implies the formation of $P$ - and $M$-type helical aggregates for $(S)-2$ and $(R)-2$, respectively. ${ }^{27}$ The formation of helical aggregates from $(S)-2$ and $(R)-2$ is in agreement with the helical structure predicted theoretically (Figure $5 \mathrm{c}$ ) and is
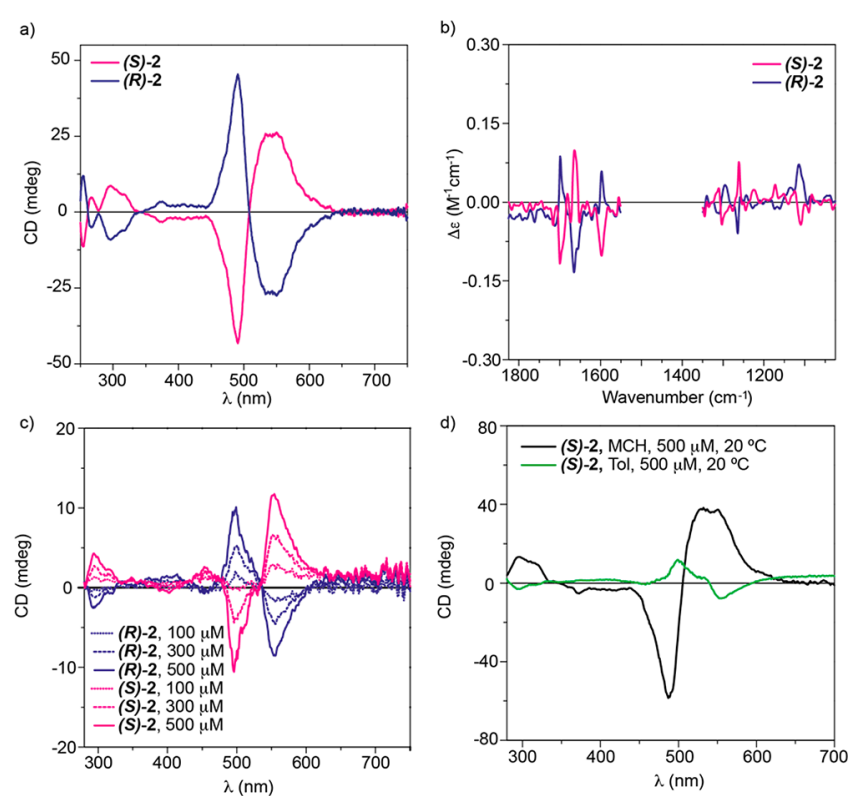

Figure 7. (a) ECD spectra of $(S)-2$ and (R)-2 in $\mathrm{MCH}\left(\mathcal{c}_{\mathrm{T}}=10 \mu \mathrm{M}\right.$, $\left.20{ }^{\circ} \mathrm{C}\right)$. (b) VCD spectra of $(S)-2$ and $(R)-2$ in $\mathrm{MCH}\left(c_{\mathrm{T}}=0.02-\right.$ $\left.0.03 \mathrm{M}, 20^{\circ} \mathrm{C}\right)$. (c) ECD spectra of $(S)-2$ and $(R)-2$ in Tol at $20{ }^{\circ} \mathrm{C}$. (d) ECD spectra of $(S)-2$ and $(R)-2$ in $\mathrm{MCH}$ and Tol $\left(c_{\mathrm{T}}=500 \mu \mathrm{M}\right.$, $20{ }^{\circ} \mathrm{C}$ ). corroborated by the corresponding VCD spectra that display a mirror-like vibrational pattern (Figure $7 \mathrm{~b}$ ). VCD spectroscopy has indeed been recognized as a suitable chiroptical tool to characterize helical supramolecular polymers. ${ }^{28}$ This mirrorlike vibrational pattern is observed for those bands at 1700 , 1665 , and $1600 \mathrm{~cm}^{-1}$, ascribable to the conjugated aromatic units, and at 1233 and $1111 \mathrm{~cm}^{-1}$, corresponding to the stretching of the alkoxy groups (Figure $7 \mathrm{~b}$ and Figure S19). On the other hand, the strong ACQ effect observed in the corresponding fluorescence measurements (Figure 4c) results in null CPL emission from the aggregates formed by $(S)-2$ and (R)-2 (Figure S17b).

Taking into account the efficient transfer of asymmetry experienced by $(S)-2$ and $(R)-2$, we checked the ability of these $\mathrm{N}$-annulated PBIs to amplify asymmetry by developing MR experiments. A linear increase in the dichroic response is observed upon plotting the variation of the ECD signal versus the ee, diagnostic of the lack of amplification of asymmetry (Figure S20). Similar findings were inferred from the corresponding $\mathrm{SaS}$ experiments performed by mixing 2 and $(S)-2$, for which a linear increase of the dichroic response upon increasing the amount of the chiral sergeant was observed (Figure S21). These studies reveal the ability of N-PBIs 2, which form supramolecular polymers governed by an isodesmic mechanism, to undergo an efficient transfer of asymmetry but a negligible amplification of asymmetry.

Finally, the influence of the solvent on the chiroptical features of the reported $\mathrm{N}$-annulated PBIs was evaluated. The solvent-solute interactions are crucial in tuning the solubility, reactivity, and structure of organic compounds and are at the forefront of the research on supramolecular polymers, since the solvent can efficiently bias the assembly/disassembly process. ${ }^{29}$ Some reports describe that the chirality embedded in solvent molecules exerts a pivotal role in controlling the helical outcome resulting from the supramolecular polymerization of achiral or chiral self-assembling units. ${ }^{30}$ However, there are scarce examples in the literature of solvent-controlled stereomutation in supramolecular polymers formed under thermodynamic control and directed by molecular design. ${ }^{31}$ In our case, we envision that the two conformers of the monomeric species of 2 , which are isoenergetic (Figure 5a), could originate helical or linear (with a small net helicity) aggregates of opposite handedness depending on the solvent conditions. To investigate this potential stereomutation, we first recomputed the stability of the optimized pentamers $\mathbf{2 A}_{\mathbf{5}}$ and $\mathbf{2} \mathbf{B}_{\mathbf{5}}$ by including $n$-hexane (as a representative solvent that emulates the $\mathrm{MCH}$ nature) or toluene as solvent. Frequency calculations were additionally carried out to estimate the free energy of the aggregation process. The self-assembly free energies per interacting pair $\left(\Delta G_{\text {bind }, n-1}^{\text {solv }}\right)$ in $n$-hexane and toluene are gathered in Table 2 . In $n$-hexane, the relative stability calculated in the gas phase is preserved, and the helical $\mathbf{2} \mathbf{B}_{5}$ aggregate is more stable than the linear $\mathbf{2} \mathrm{A}_{\mathbf{5}}$ aggregate by 8.30

Table 2. Self-Assembly Free Energy $\left(\Delta G_{\text {bind }, n-1}^{\text {solv }}\right.$, in $\left.\mathrm{kJ} \mathrm{mol}^{-1}\right)$ Estimated for the Two Most Stable Aggregates of 2 in $n$ Hexane and Toluene Solution at the GFN2-xTB/GBSA Level

$\begin{array}{ccc}\text { aggregate } & \Delta G_{\text {bind, } n-1}^{n-\text { hexane }} & \Delta G_{\text {bind }, n-1}^{\text {tolune }} \\ \mathbf{2 A}_{5} & -19.63 & -24.94 \\ \mathbf{2 B}_{5} & -27.93 & -24.35\end{array}$


$\mathrm{kJ} \mathrm{mol}^{-1}$. In contrast, the stability is reversed in Tol and the linear aggregate is slightly more stable by $0.59 \mathrm{~kJ} \mathrm{~mol}^{-1}$. The relative stability of the aggregates of compound $\mathbf{2}$ therefore depends on the solvent nature and, when the most stable aggregate in each solvent is considered, $\Delta G_{\text {bind, } n-1}^{n \text { hexane }}$ is calculated to be more negative than $\Delta G_{\text {bind } n-1}^{\text {tolue }}$ by $\sim 3.0 \mathrm{~kJ} \mathrm{~mol}^{-1}$. These results thus point to a higher tendency of compounds 2 to selfassemble in $\mathrm{MCH}$ than in Tol, in good accord with the experimental evidence.

The supramolecular mechanism of the self-assembling process of $\mathrm{N}$-annulated PBIs 2 was furthermore investigated by performing interaction energy calculations for regular oligomers of increasing size (from $n=1$ to $n=50$ monomers) at the GFN2-xTB level in the presence of the solvent. Theoretical calculations on $\mathbf{2} \mathbf{A}_{5}$-type aggregates in toluene reveal that the binding energy per interacting pair $\left(\Delta E_{\mathrm{bind}, n-1}\right)$ barely changes with the oligomer size (Figure S22), which is a clear indication of an isodesmic supramolecular polymerization mechanism. Similar results are obtained for $\mathbf{2 B}_{5}$-type oligomers in $n$-hexane (Figure S22), with even a small $\Delta E_{\text {bind }, n-1}$ increase of $\sim 5 \mathrm{~kJ} \mathrm{~mol}^{-1}$ from $n=2$ to $n=5$ in this case. The absence of cooperativity predicted in the supramolecular growth of 2 stems from the nature of the noncovalent interactions stabilizing the self-assembly (mainly $\pi$-stacking interactions), with no directional electrostatic forces such as $\mathrm{H}$-bonding or dipole-dipole interactions. ${ }^{32}$

Taking into account the previous report on the stereomutation experienced by a comparable $\mathrm{PBI}^{33}$ and the results of the theoretical calculations, we experimentally checked the possibility of $(S)-2$ and $(R)-2$ of achieving a solvent-controlled stereomutation by registering the ECD spectra in Tol as solvent. Using concentrations as low as those utilized in $\mathrm{MCH}$ (Figure 7a), no ECD response was observed. However, when the concentration was increased to $c_{\mathrm{T}}=100 \mu \mathrm{M}$, it was possible to register a weak but noticeable ECD spectrum (Figure 7c), showing patterns opposite to those recorded in $\mathrm{MCH}$ (Figure 7a). It is worth noting that the UV-vis spectrum recorded at $\mathcal{c}_{\mathrm{T}}=100 \mu \mathrm{M}$ reveals a degree of aggregation that increases upon increasing the concentration up to $500 \mu \mathrm{M}$, as the higher intensity observed in the dichroic response demonstrates (Figure $7 \mathrm{c}$ and Figure S23). At $c_{\mathrm{T}}=$ $500 \mu \mathrm{M}$, the dichroic pattern of $\mathrm{N}$-annulated PBIs 2 in Tol is opposite to that registered in $\mathrm{MCH}$ (Figure $7 \mathrm{~d}$ ) and the sample is completely aggregated, as supported by the quenching of the fluorescence emission (Figure 4c).

The influence of the type of aggregation on the circular dichroism properties of $\mathrm{N}$-annulated PBIs was also analyzed by means of TD-DFT calculations. To unveil the effect of the rotational dihedral angle $(\theta)$ along the growth axis, the theoretical ECD spectrum was calculated for a dimer of the Nannulated PBI core, in which the angle $\theta$ ranges from 0 to $10^{\circ}$ (Figure S24). Theoretical calculations indicate that a significant dichroic signal is obtained even at small dihedral angles $\left(>2^{\circ}\right)$. This suggests that not only helical aggregates with a large $\theta$ value but also linear stacking aggregates with a small net $\theta$ value, promoted by the point chirality element embedded in the peripheral groups, may afford a dichroic signal. The different dichroic reponses observed for chiral 2 in $\mathrm{MCH}$ and Tol can thus be explained by the different aggregation modes of $\mathbf{2}$ in these two solvents. In toluene, theoretical calculations predict that the most stable aggregate $\mathbf{2} \mathbf{A}_{\mathbf{5}}$ is an almost regular linear H-type self-assembly and gives rise to a small dichroic signal (Figure S25) in agreement with the experiment (Figure $7 \mathrm{c}, \mathrm{d}$ ). In contrast, in $n$-hexane (modeling $\mathrm{MCH}$ ), the most stable aggregate is predicted to be $\mathbf{2} \mathbf{B}_{5}$, which corresponds to a well-defined helical arrangement with a rotational dihedral angle $\theta$ of $35^{\circ}$ and thus shows an intense dichroic pattern (Figure S25) similar to that found experimentally for $(S)-2$ and $(R)-2$ in $\mathrm{MCH}$ (Figure $7 \mathrm{c}, \mathrm{d}$ ).

\section{CONCLUSIONS}

The synthesis of two series of $\mathrm{N}$-annulated PBIs endowed with peripheral trialkoxyphenyl groups directly attached to the imide nitrogens of the PBI core (2) or linked by a propionate spacer (1) is reported. A complete set of spectroscopic measurements and theoretical calculations demonstrate the huge influence that the distance and conformational flexibility of the peripheral groups exert on the optical and chiroptical properties and on the supramolecular polymerization mechanism of the resulting self-assembly. Compounds 1 present a cooperative supramolecular polymerization that yields highly emissive J-type aggregates with negligible chiroptical (ECD, VCD, and CPL) response for the chiral congeners ( $S$ )-1 and (R)-1. The staircase-like aggregation mode calculated for the supramolecular polymers formed from $\mathbf{1}$ and the dipoledipole interactions between adjacent $\mathrm{C}=\mathrm{O}$ groups along the stack justify these features. In contrast, bringing the peripheral side groups closer to the $\mathrm{N}$-annulated PBI core drastically changes the self-assembling features of compounds 2 . In this case, the supramolecular polymerization is governed by an isodesmic mechanism that gives rise to $\mathrm{H}$-type aggregates exhibiting a strong ACQ effect which, therefore, show low emissive properties. Chiral ( $S)-2$ and $(R)-2$ experience an efficient transfer of asymmetry to afford $P$ - and $M$-type aggregates, respectively, but no amplification of asymmetry is achieved by performing MR and $\mathrm{SaS}$ experiments. Finally, a solvent-controlled stereomutation has been demonstrated for chiral (S)-2 and (R)-2, which form supramolecular polymers with different structures depending on the solvent utilized ( $\mathrm{MCH}$ or Tol). This stereomutation has been accounted for by considering the two possible conformations of the peripheral side chains in compounds 2 , eclipsed or staggered. These conformations lead to linear or helical self-assemblies, respectively, of opposite stability depending on the solvent conditions. The synergy between the experimental evidence and the theoretical calculations presented herein contribute to elaborate structure/function relationships useful in predicting relevant features of supramolecular polymers.

\section{ASSOCIATED CONTENT}

\section{Supporting Information}

The Supporting Information is available free of charge at https://pubs.acs.org/doi/10.1021/jacs.1c06125.

Full experimental details and characterization, additional spectroscopic measurements, and theoretical calculations, including Figures S1-S25 (PDF)

\section{AUTHOR INFORMATION}

\section{Corresponding Authors}

Enrique Ortí - Instituto de Ciencia Molecular (ICMol), Universidad de Valencia, 46980 Paterna, Spain; ○ orcid.org/0000-0001-9544-8286; Email: enrique.orti@ uv.es

Luis Sánchez - Departamento de Química Orgánica, Facultad de Ciencias Quimicas, Universidad Complutense de Madrid, 
28040 Madrid, Spain; ๑ orcid.org/0000-0001-7867-8522;

Email: lusamar@quim.ucm.es

\section{Authors}

Manuel A. Martínez - Departamento de Química Orgánica, Facultad de Ciencias Quimicas, Universidad Complutense de Madrid, 28040 Madrid, Spain

Azahara Doncel-Giménez - Instituto de Ciencia Molecular (ICMol), Universidad de Valencia, 46980 Paterna, Spain

Jesús Cerdá - Instituto de Ciencia Molecular (ICMol), Universidad de Valencia, 46980 Paterna, Spain

Joaquín Calbo - Instituto de Ciencia Molecular (ICMol), Universidad de Valencia, 46980 Paterna, Spain; ๑ orcid.org/0000-0003-4729-0757

Rafael Rodríguez - Univ Rennes, CNRS, ISCR (Institut des Sciences Chimiques de Rennes), F-35000 Rennes, France; ๑ orcid.org/0000-0002-8588-7776

Juan Aragó - Instituto de Ciencia Molecular (ICMol), Universidad de Valencia, 46980 Paterna, Spain; (-) orcid.org/0000-0002-0415-9946

Jeanne Crassous - Univ Rennes, CNRS, ISCR (Institut des Sciences Chimiques de Rennes), F-35000 Rennes, France; ๑ orcid.org/0000-0002-4037-6067

Complete contact information is available at: https://pubs.acs.org/10.1021/jacs.1c06125

\section{Author Contributions}

The manuscript was written through contributions of all authors. All authors have given approval to the final version of the manuscript.

\section{Notes}

The authors declare no competing financial interest.

\section{ACKNOWLEDGMENTS}

Dedicated to Prof. Nazario Martín on the occasion of his 65th anniversary. Financial support by the MICINN of Spain (PID2020-113512GB-I00, PGC2018-099568-B-I00, and Unidad de Excelencia María de Maeztu CEX2019-000919-M), the Generalitat Valenciana (PROMETEO/2020/077 and SEJI/ 2018/035), the Comunidad de Madrid (NanoBIOCARGO, P2018/NMT-4389), and European Feder funds (PGC2018099568-B-I00) is acknowledged. M.A.M. and J.A. are indebted to the MICINN for their predoctoral and Ramón-y-Cajal (RyC-2017-23500) fellowships. J.C. and A.D.-G. acknowledge the Generalitat Valenciana for their $\mathrm{I}+\mathrm{d}+\mathrm{i}$ postdoctoral (APOSTD/2017/081) and predoctoral fellowships. R.R. thanks the Xunta de Galicia for a Postdoctoral Fellowship.

\section{ABBREVIATIONS}

PBI, perylene bisimide; ACQ aggregation-caused quenching; $\mathrm{SaS}$, sergeants and soldiers; MR, majority rules; SP, supramolecular polymerization; CT, charge transfer; ECD, electronic circular dichroism; VCD, vibrational circular dichroism; $\mathrm{MCH}$, methylcyclohexane; AFM, atomic force microscopy; HOPG, highly oriented pyrolytic graphite; EQ equilibrium; GBSA, generalized Born and surface area continuum solvation model.

\section{REFERENCES}

(1) Fouquey, C.; Lehn, J. M.; Levelut, A.-M. Molecular recognition directed self-assembly of supramolecular liquid crystalline polymers from complementary chiral components. Adv. Mater. 1990, 2, 254257.
(2) (a) Scheibe, G. Über die veränderlichkeit der absorptionsspektren in lösungen und dienebenvalenzen als ihre ursache. Angew. Chem. 1937, 50, 212-219. (b) Jelley, E. E. Spectral absorption and fluorescence of dyes in the molecular state. Nature 1936, 138, 10091010.

(3) Klug, A. The tobacco mosaic virus particle: structure and assembly. Philos. Trans. R. Soc., B 1999, 354, 531-535.

(4) (a) Brunsveld, L.; Folmer, B. J. B.; Meijer, E. W.; Sijbesma, R. P. Supramolecular polymers. Chem. Rev. 2001, 101, 4071-4098. (b) Wehner, M.; Würthner, F. Supramolecular polymerization through kinetic pathway control and living chain growth. Nat. Rev. 2020, 4, 38-53.

(5) (a) De Greef, T. F. A.; Smulders, M. M. J.; Wolffs, M.; Schenning, A. P. H. J.; Sijbesma, R. P.; Meijer, E. W. Supramolecular polymerization. Chem. Rev. 2009, 109, 5687-5754. (b) ten Eikelder, H. M. M.; Markvoort, A. J. Mass-Balance Models for Scrutinizing Supramolecular (Co)polymerizations in Thermodynamic Equilibrium. Acc. Chem. Res. 2019, 52, 3465-3474. (c) Gershberg, J.; Fennel, F.; Rehm, T. H.; Lochbrunner, S.; Würthner, F. Anticooperative supramolecular polymerization: a new $\mathrm{K} 2-\mathrm{K}$ model applied to the self-assembly of perylene bisimide dye proceeding via well-defined hydrogen-bonded dimers. Chem. Sci. 2016, 7, 17291737.

(6) Matern, J.; Dorca, Y.; Sánchez, L.; Fernández, G. Revising Complex Supramolecular Polymerization under Kinetic and Thermodynamic Control. Angew. Chem., Int. Ed. 2019, 58, 16730-16740.

(7) (a) Smulders, M. M. J.; Schenning, A. P. H. J.; Meijer, E. W. Tuning the extent of chiral amplification by tempera-ture in a dynamic supramolecular polymer. J. Am. Chem. Soc. 2008, 130, 606611. (b) García, F.; Viruela, P. M.; Matesanz, E.; Ortí, E.; Sánchez, L. Cooperative supramolecular polymerization and amplification of chirality in $C_{3}$-symmetrical OPE-based trisamides. Chem. - Eur. J. 2011, 17, 7755-7759. (c) García, F.; Sánchez, L. Structural rules for the chiral supramolecular organization of ope-based discotics: induction of helicity and amplification of chirality. J. Am. Chem. Soc. 2012, 134, 734-742. (d) García, F.; Korevaar, P. A.; Verlee, A.; Meijer, E. W.; Palmans, A. R. A.; Sánchez, L. The influence of $\pi$ conjugated moieties on the thermodynamics of cooperatively selfassembling tricarboxamides. Chem. Commun. 2013, 49, 8674-8676. (e) Rödle, A.; Ritschel, B.; Mück-Lichtenfeld, C.; Stepanenko, V.; Fernández, G. Influence of Ester versus Amide Linkers on the Supramolecular Polymerization Mechanisms of Planar BODIPY Dyes. Chem. - Eur. J. 2016, 22, 15772-15777.

(8) Kulkarni, C.; Balasubramanian, S.; George, S. J. What Molecular Features Govern the Mechanism of Supramolecular Polymerization? ChemPhysChem 2013, 14, 661-673.

(9) (a) Kulkarni, C.; Bejagam, K. K.; Senanayak, S. P.; Narayan, K. S.; Balasubramanian, S.; George, S. J. Dipole-Moment-Driven Cooperative Supramolecular Polymerization. J. Am. Chem. Soc. 2015, 137, 3924-3932. (b) Sarkar, A.; Sasmal, R.; Empereurmot, C.; Bochicchio, D.; Kompella, S. V. K.; Sharma, K.; Dhiman, S.; Sundaram, B.; Agasti, S. S.; Pavan, G. M.; George, S. J. Self-Sorted, Random, and Block Supramolecular Copolymers via Sequence Controlled, Multicomponent Self-Assembly. J. Am. Chem. Soc. 2020, $142,7606-7617$

(10) Huang, S.; Yu, H.; Li, Q. Supramolecular Chirality Transfer toward Chiral Aggregation: Asymmetric Hierarchical Self-Assembly. Adv. Sci. 2021, 8 (1-20), 2002132.

(11) (a) Palmans, A. R. A.; Meijer, E. W. Amplification of chirality in dynamic supramolecular aggregates. Angew. Chem., Int. Ed. 2007, 46, 8948-8968. (b) Dorca, Y.; Greciano, E. E.; Valera, J. S.; Gómez, R.; Sánchez, L. Hierarchy of Asymmetry in Chiral Supramolecular Polymers: Toward Functional, Helical Supramolecular Structures. Chem. - Eur. J. 2019, 25, 5848-5864. (c) Valera, J. S.; Gómez, R.; Sánchez, L. Supramolecular polymerization of [5]helicenes. Consequences of self-assembly on configurational stability. Org. Lett. 2018, 20, 2020-2023. (d) Buendía, J.; Greciano, E. E.; Sánchez, L. Influence of axial and point chirality in the chiral self-assembly of twin $\mathrm{N}$-annulated perylenecarboxamides. J. Org. Chem. 2015, 80, 12444- 
1245. (e) Aparicio, F.; Nieto-Ortega, B.; Nájera, F.; Ramírez, F. J.; López Navarrete, J. T.; Casado, J.; Sánchez, L. Inversion of supramolecular helicity in oligo-p-phenylene-based supramolecular polymers: influence of molecular atropisomerism. Angew. Chem., Int. Ed. 2014, 53, 1373-1377. (f) Xie, Z.; Stepanenko, V.; Radacki, K.; Würthner, F. Chiral J-aggregates of atropo-enantiomeric perylene bisimides and their self-sorting behavior. Chem. - Eur. J. 2012, 18, $7060-7070$

(12) (a) Smulders, M. M. J.; Filot, I. A. W.; Leenders, J. M. A.; van der Schoot, P.; Palmans, A. R. A.; Schenning, A. P. H. J.; Meijer, E. W. Tuning the extent of chiral amplification by temperature in a dynamic supramolecular polymer. J. Am. Chem. Soc. 2010, 132, 611-619. (b) Smulders, M. M. J.; Stals, P. J. M.; Mes, T.; Paffen, T. F. E.; Schenning, A. P. H. J.; Palmans, A. R. A.; Meijer, E. W. Probing the limits of the majority-rules principle in a dynamic supramolecular polymer. J. Am. Chem. Soc. 2010, 132, 620-626. (c) Greciano, E. E.; Calbo, J.; Buendía, J.; Cerdá, J.; Aragó, J.; Ortí, E.; Sánchez, L. Decoding the Consequences of Increasing the Size of SelfAssembling Tricarboxamides on Chiral Amplification. J. Am. Chem. Soc. 2019, 141, 7463-7472. (d) Dorca, Y.; Sánchez-Naya, R.; Cerdá, J.; Calbo, J.; Aragó, J.; Gómez, R.; Ortí, E.; Sánchez, L. Impact of Molecular Size and Shape on the Supramolecular Co-Assembly of Chiral Tricarboxamides: A Comparative Study. Chem. - Eur. J. 2020, 26, 14700-14707.

(13) (a) Buendía, J.; García, F.; Yélamos, B.; Sánchez, L. Transfer and amplification of chirality in Phe-based C3-symmetric non-ionic amphiphiles. Chem. Commun. 2016, 52, 8830-8833. (b) Kulkarni, C.; Korevaar, P. A.; Bejagam, K. K.; Palmans, A. R. A.; Meijer, E. W.; George, S. J. Solvent Clathrate Driven Dynamic Stereomutation of a Supramolecular Polymer with Molecular Pockets. J. Am. Chem. Soc. 2017, 139, 13867-13875.

(14) Greciano, E. E.; Calbo, J.; Ortí, E.; Sánchez, L. N-Annulated Perylene Bisimides to Bias the Differentiation of Metastable Supramolecular Assemblies into J- and H-Aggregates. Angew. Chem., Int. Ed. 2020, 59, 17517-17524.

(15) Mei, J.; Leung, N. L. C.; Kwok, R. T. K.; Lam, J. W. Y.; Tang, B. Z. Aggregation-Induced Emission: Together We Shine, United We Soar! Chem. Rev. 2015, 115, 11718-11940.

(16) Würthner, F.; Saha-Möller, C. R.; Fimmel, B.; Ogi, S.; Leowanawat, P.; Schmidt, D. Perylene Bisimide Dye Assemblies as Archetype Functional Supramolecular Materials. Chem. Rev. 2016, 116, 962-1052.

(17) ten Eikelder, H. M. M.; Markvoort, A. J.; de Greef, T. F. A.; Hilbers, P. A. J. An equilibrium model for chiral amplification in supramolecular polymers. J. Phys. Chem. B 2012, 116, 5291-5301.

(18) Würthner, F.; Kaiser, T. E.; Saha-Möller, C. R. J-Aggregates: From Serendipitous Discovery to Supramolecular Engineering of Functional Dye Materials. Angew. Chem., Int. Ed. 2011, 50, 33763410.

(19) Bannwarth, C.; Ehlert, S.; Grimme, S. GFN2-xTB-An Accurate and Broadly Parametrized Self-Consistent Tight-Binding Quantum Chemical Method with Multipole Electrostatics and Density-Dependent Dispersion Contributions. J. Chem. Theory Comput. 2019, 15, 1652-1671.

(20) Hestand, N. J.; Spano, F. C. Expanded Theory of H- and JMolecular Aggregates: The Effects of Vibronic Coupling and Intermolecular Charge Transfer. Chem. Rev. 2018, 118, 7069-7163.

(21) Hestand, N. J.; Spano, F. C. Interference between Coulombic and CT-mediated couplings in molecular aggregates: $\mathrm{H}$ - to $\mathrm{J}$ aggregate transformation in perylene-based $\pi$-stacks. J. Chem. Phys. 2015, 143, 244707.

(22) Hong, Y.; Kim, J.; Kim, W.; Kaufmann, C.; Kim, H.; Würthner, F.; Kim, D. Efficient Multiexciton State Generation in ChargeTransfer-Coupled Perylene Bisimide Dimers via Structural Control. J. Am. Chem. Soc. 2020, 142, 7845-7857.

(23) Palmans, A. R. A.; Meijer, E. W.; Denmark, S. E. Stereochemical language in supramolecular polymer chemistry: How we can do better. J. Polym. Sci. 2021, 59, 1171-1174.
(24) (a) Ghosh, S.; Li, X.-Q.; Stepanenko, V.; Würthner, F. Control of $\mathrm{H}$ - and J-Type $\mathrm{p}$ Stacking by Peripheral Alkyl Chains and SelfSorting Phenomena in Perylene Bisimide Homo- and Heteroaggregates. Chem. - Eur. J. 2008, 14, 11343-11357. (b) Huber, V.; Sengupta, S.; Würthner. Structure-Property Relationships for SelfAssembled Zinc Chlorin Light-Harvesting Dye Aggregates. Chem. Eur. J. 2008, 14, 7791-7807. (c) Ribó, J. M.; Crusats, J.; Sagués, F.; Claret, J.; Rubires, R. Chiral Sign Induction by Vortices During the Formation of Mesophases in Stirred Solutions. Science 2001, 292, 2063-2066.

(25) (a) Valera, J. S.; Gómez, R.; Sánchez, L. Kinetic Traps to Activate Stereomutation in Supramolecular Polymers. Angew. Chem., Int. Ed. 2019, 58, 510-514. (b) Dorca, Y.; Naranjo, C.; Ghosh, G.; Gómez, R.; Fernández, G.; Sánchez, L. Unconventional Chiral Amplification in Luminescent Supramolecular Polymers Based on Trisbiphenylaminetricarboxamides. Org. Materials 2020, 02, 041046.

(26) (a) Sato, T.; Terao, K.; Teramoto, A.; Fujiki, M. On the Composition-Driven Helical Screw-Sense Inversion of Chiral-Achiral Random Copolymers. Macromolecules 2002, 35, 5355-5357. (b) Nagata, Y.; Nishikawa, T.; Suginome, M. Solvent Effect on the Sergeants-and-Soldiers Effect Leading to Bidirectional Induction of Single-Handed Helical Sense of Poly(quinoxaline-2,3-diyl)s Copolymers in Aromatic Solvents. ACS Macro Lett. 2016, 5, 519-522.

(27) (a) Harada, N.; Nakanishi, K. Optical rotatory power of the benzoate group. J. Am. Chem. Soc. 1968, 90, 7351-7352. (b) Harada, N.; Chen, S.-M. L.; Nakanishi, K. Quantitative definition of exciton chirality and the distant effect in the exciton chirality method. J. Am. Chem. Soc. 1975, 97, 5345-5352. (c) Swathi, K.; Sissa, C.; Painelli, A.; Thomas, K. G. Supramolecular chirality: a caveat in assigning the handedness of chiral aggregates. Chem. Commun. 2020, 56, 82818284.

(28) (a) Greciano, E. E.; Rodríguez, R.; Maeda, K.; Sánchez, L. Disclosing chirality in consecutive supramolecular polymerizations: chiral induction by light in $\mathrm{N}$-annulated perylenetetracarboxamides. Chem. Commun. 2020, 56, 2244-2247. (b) Nieto-Ortega, B.; García, F.; Longhi, G.; Castiglioni, E.; Calbo, J.; Abbate, S.; López Navarrete, J. T.; Ramírez, F. J.; Ortí; Sánchez, L.; Casado, J. On the handedness of helical aggregates of C3-tricarboxamides: a multichiroptical characterization. Chem. Commun. 2015, 51, 9781-9784. (c) Smulders, M. M. J.; Buffeteau, T.; Cavagnat, D.; Wolffs, M.; Schenning, A. P. H. J.; Meijer, E. W. $\mathrm{C}_{3}$-Symmetrical Self-Assembled Structures Investigated by Vibrational Circular Dichroism. Chirality 2008, 20, 1016-1022. (d) Brizard, A.; Berthier, D.; Aimé, C.; Buffeteau, T.; Cavagnat, D.; Ducasse, L.; Huc, I.; Oda, R. Molecular and supramolecular chirality in gemini-tartrate amphiphiles studied by electronic and vibrational circular dichroisms. Chirality 2009, 21, E153-E162.

(29) Mabesoone, M. F. J.; Palmans, A. R. A.; Meijer, E. W. SoluteSolvent Interactions in Modern Physical Organic Chemistry: Supramolecular Polymers as a Muse. J. Am. Chem. Soc. 2020, 142, 19781-19798.

(30) (a) Ślęczkowski, M. L.; Mabesoone, M. F. J.; Ślęczkowski, P.; Palmans, A. R. A.; Meijer, E. W. Competition between chiral solvents and chiral monomers in the helical bias of supramolecular polymers. Nat. Chem. 2021, 13, 200-209. (b) George, S. J.; Tomovic, Z.; Schenning, A. P. H. J.; Meijer, E. W. Insight into the chiral induction in supramolecular stacks through preferential chiral solvation. Chem. Commun. 2011, 47, 3451-3453. (c) Isare, B.; Linares, M.; Zargarian, L.; Fermandjian, S.; Miura, M.; Motohashi, S.; Vanthuyne, N.; Lazzaroni, R.; Bouteiller, L. Chirality in Dynamic Supramolecular Nanotubes Induced by a Chiral Solvent. Chem. - Eur. J. 2010, 16, 173-177. (d) Palmans, A. R. A.; Vekemans, J. A. J. M.; Havinga, E. E.; Meijer, E. W. Sergeants-and-Soldiers Principle in Chiral Columnar Stacks of Disc-Shaped Molecules with $\mathrm{C}_{3}$ Symmetry. Angew. Chem., Int. Ed. Engl. 1997, 36, 2648-2651.

(31) Kulkarni, C.; Korevaar, P. A.; Bejagam, K. K.; Palmans, A. R. A.; Meijer, E. W.; George, S. J. Solvent Clathrate Driven Dynamic 
Stereomutation of a Supramolecular Polymer with Molecular Pockets.

J. Am. Chem. Soc. 2017, 139, 13867-13875.

(32) Palmans, A. R. A.; Meijer, E. W. Amplification of chirality in dynamic supramolecular aggregates. Angew. Chem., Int. Ed. 2007, 46, 8948-8968.

(33) Dehm, V.; Chen, Z.; Baumeister, U.; Prins, P.; Siebbeles, L. D. A.; Würthner, F. Helical Growth of Semiconducting Columnar Dye Assemblies Based on Chiral Perylene Bisimides. Org. Lett. 2007, 9, $1085-1088$. 